\title{
Heat, heatwaves and cardiorespiratory hospital admissions in Helsinki,
} Finland.

Hasan Sohail ${ }^{1,2^{*}}$, Pekka Tiittanen $^{2}$, Virpi Kollanus ${ }^{2}$, Alexandra Schneider ${ }^{3}$, Timo Lanki ${ }^{1,2}$

${ }^{1}$ University of Eastern Finland, Department of Environmental and biological sciences, Yliopistonranta 1 a P.O. Box 1627, Fl-70211, Kuopio, Finland.

${ }^{2}$ Department of Health Security, National Institute for Health and Welfare (THL), 70210 Kuopio, Finland

${ }^{3}$ Institute of Epidemology, Helmontz Zentrum München, German Research Centre for Environmental Health, Neuherberg, Germany

*Correspondence: hasan.sohail07@gmail.com

\section{Abstract:}

Background: There is a lack of knowledge concerning the effects of ambient heat exposure on morbidity in Northern Europe. Therefore, this study aimed to evaluate the relationships of daily summer-time temperature and heatwaves with cardiorespiratory hospital admissions in the Helsinki metropolitan area, Finland.

Methods: Time-series models adjusted for potential confounders such as air pollution were used to investigate the associations of daily temperature and heatwaves with cause-specific cardiorespiratory hospital admissions, during summer months of 2001-2017. Daily number of hospitalizations was obtained from the national hospital discharge register, weather information from the Finnish Meteorological Institute.

Results: Increased daily temperature was associated with decreased risk of total respiratory hospital admissions and asthma. Heatwave days were associated with $20.5 \%$ (95\% Cl: 6.9, 35.9) increased risk of pneumonia admissions and during long or intense heatwaves also with total respiratory admissions in the oldest age group ( $\geq 75$ years). There were also suggestive positive associations between heatwave days and admissions due to myocardial infarction and cerebrovascular diseases. In contrast, risk of arrhythmia admissions was decreased $20.8 \%$ ( $95 \% \mathrm{Cl}$ : 8.0, 31.8) during heatwaves.

Conclusions: Heatwaves, rather than single hot days, are a health threat affecting the morbidity even in a Northern climate.

Keywords: Heat; Heatwave; Cardiovascular diseases; Respiratory diseases; Hospital admissions; Climate change; ambient temperature; Public health; time series; summer months 


\section{Introduction}

Global warming is anticipated to increase the frequency and intensity of hot days and heatwaves (1). Exposure to high temperature can lead to many types of adverse physiological changes in the human body $(2,3)$. Therefore, evaluating the association of heat exposure with human health is of paramount importance in a changing climate.

The positive association between ambient heat exposure and mortality has been well established in countries around the world $(4,5,6,7,8)$. Results from mortality studies have been the basis for the development of heat-health warning systems and action plans (9). However, there have been far less research on the associations between heat exposure and hospital admissions. This is because the hospital data is typically less easily accessible than mortality data. The majority of the studies on hospital admissions have included either all-cause admissions or the broad diagnosis categories of cardiovascular and respiratory diseases.

Interestingly, studies between heat and hospital admissions have exhibited mixed results $(10,11)$. In addition to hospital admissions due to health conditions directly related to heat stress, fluid or electrolyte imbalance $(12,13,14)$, respiratory admissions are commonly found to be associated with heatwaves $(15,16,17)$. Associations have also been detected with hospital admissions due to some less studied disease outcomes $(18,19,20,21)$. Cardiovascular diseases have shown a weak association with hot days in some studies $(11,22)$, but no such association was found in a metaanalysis by Turner et al (23). Hospital admission studies have focused on extreme heat leaving the need to investigate also the effects of moderate heat (10).

Polar amplification in the northern latitudes is making Northern Europe especially susceptible to the effects of global warming (24). So far, only few studies have been carried out to evaluate the association of high ambient temperatures with hospital admissions in Northern European countries $(16,25,26,27)$. Therefore, this study investigates the association of heat and heatwaves with cardiorespiratory hospital admissions in the Helsinki metropolitan area, Finland. Understanding how morbidity, and not just mortality, is associated with heat exposure in Northern Europe is crucial for formulating adaptation strategies.

\section{Methodology:}

\section{Study design and population}

Our time series study evaluated associations between daily mean temperature and, daily number of non-elective hospital admissions in the Helsinki metropolitan area, Finland, in June-August 2001-2017. The Helsinki metropolitan area includes the cities of Helsinki, Vantaa, Espoo and Kauniainen, population size of approximately 1.15 million during the period 2001-2017 (28).

\section{Health and environmental data}

Health data was obtained from a national registry containing information on daily hospital admissions. The study contained information on daily non-elective hospital admission in JuneAugust 2001-2017 for all cardiovascular diseases (CVD: 100-199), all respiratory diseases (J00-J99), myocardial infarction (MI: I21-I22), ischemic heart disease (IHD: 20-I25), cerebrovascular diseases 
(160-161, 163-164), arrhythmia (146.0, 146.9, 147-149), asthma (J45, J46), chronic obstructive pulmonary disease (COPD: J41, J44), and pneumonia (J12-J15, J16.8, J18) in specific age groups (all-ages, 18-64, 65-74 and 75 plus).

Exposures of interest in the study were daily mean temperature and heatwaves.

Daily weather data was provided by the Finnish Meteorological Institute. Data was collected using a fixed weather station at the Helsinki-Vantaa airport. Air pollution data was obtained from the Helsinki Region Environmental Services Authority, and included information on nitrogen dioxide $\left(\mathrm{NO}_{2}\right)$, ozone $\left(\mathrm{O}_{3}\right)$, inhalable particulate matter $\left(\mathrm{PM}_{10}\right.$; aerodynamic diameter $\left.\leq 10 \mu \mathrm{m}\right)$ and fine particulate matter $\left(\mathrm{PM}_{2.5}\right.$; aerodynamic diameter $\left.\leq 2.5 \mu \mathrm{m}\right)$. For $\mathrm{NO}_{2}, \mathrm{PM}_{10}$ and $\mathrm{PM}_{2.5}$, Kallio urban background station was used. Daily averages were calculated from 1-hour values and at least 18 hourly values had to be available, otherwise daily average was defined as missing. For ozone $\left(\mathrm{O}_{3}\right)$, 8-hour moving averages were calculated using hourly data from Luukki measurement site which is an aerial background station. At least, 6 hourly values had to be available, otherwise 8 hour moving average were defined as missing. Second, maximum daily 8-hour moving averages were calculated from 8-hour moving averages and at least 18 values had to be available, otherwise the maximum 8-hour average was defined as missing. Data on daily pollen counts was provided by the Aerobiology Unit, University of Turku.

\section{Statistical analysis}

Multivariate Poisson time series regression models were used to evaluate whether daily number of hospital admissions is associated with daily mean temperature. We used daily mean temperature and heatwaves separately as exposure variables in the models. Previous studies have reported that the effect of high temperature on hospital admissions take place only with a short delay. Therefore, we looked at individual daily lags from lag 0 (exposure during the day of admission) to lag 5 (exposure 5 days prior to the day of admission). We used the average of lags 0 and 1 as the main exposure variable.

The effects of heatwaves (extended heat exposure) were investigated by adding an indicator variable for heatwaves in the model. There is no standard definition for a heatwave, but varying combinations of intensity and duration have been used in earlier studies. In the current study, heatwaves were defined using $90^{\text {th }}$ and $95^{\text {th }}$ percentile cutoff points for mean daily temperature in May-August 2001-2017. For heatwaves that lasted nine days or less, the cutoff temperature had to be exceeded in each consecutive day. For heatwaves that lasted ten days or longer, one day with temperature below the cutoff point after the tenth day was allowed, if the cutoff temperature was then again exceeded for at least two consecutive days. At the $90^{\text {th }}$ percentile cutoff point, heatwaves were defined as periods lasting for four or more days, and analyses were also conducted separately for short heatwaves (4-7 days) and long heatwaves (10 or more days). At the $95^{\text {th }}$ cutoff point, length of heatwave was 3 or more days.

Time trends were modelled with a three-way interaction between year, month and day of the week and an indicator for holidays. Linear terms for air pollutants $\left(\mathrm{NO}_{2}, \mathrm{O}_{3}, \mathrm{PM}_{10}\right.$ and $\left.\mathrm{PM} \mathrm{M}_{2.5}\right)$, 
relative humidity $(\mathrm{RH})$ and barometric pressure $(\mathrm{BP})$ were introduced as potential confounders (selected a priori) in the model. Both lag 0 and the average of lags 1-3 were used for air pollutants, relative humidity and barometric pressure. Moreover, pollen count (a sum of alder, birch, mug wort and grasses) was taking into account using two indicators. The daily count (lag 0) and the sum of count on three previous days (lags 1-3) were categorized into two categories using 100 grains/m3 as a cutoff.

Poisson regression was applied using the glm function in the stats package in $\mathrm{R}$ ( $\mathrm{R}$ Development Core Team, Vienna, Austria)(29). Effect estimates were reported as percentage change with $95 \%$ confidence intervals. We performed analysis separately for all ages, 18-64, 65-74 and 75 plus. The shape of association of continuous exposure and covariates were checked with the gam function in the mgcv package using thin plate regression splines. This technique has advantage of not requiring the limitation of choosing the knot locations.

As a sensitivity analysis, we run separate models again for daily average temperature by removing days with low temperature $\left(1^{\text {st }}\right.$ percentile, $\left.9.4 \mathrm{C}^{\circ}\right)$ and days with high temperature $\left(99^{\text {th }}\right.$ percentile, $24.5 \mathrm{C}^{\circ}$ ). We also run the models again without air pollutant variables to check the robustness of our results.

\section{Results}

Table 1 and Table 2 show descriptive statistics for the outcome and exposure variables used in this study. The majority (46.3\%) of all the hospital admissions occurred among persons of 75 years of age and above. The mean daily temperature during the study period was $15.3^{\circ} \mathrm{C}$. The average daily mean humidity was 70.1\%. Daily mean concentrations of $\mathrm{PM}_{2.5}, \mathrm{PM}_{10}, \mathrm{O}_{3}$ and $\mathrm{NO}_{2}$ were 7.6, 14.1, 80.3 and $17.8 \mu \mathrm{g} / \mathrm{m}^{3}$, respectively.

Table 1: Daily number of hospital admissions for cardiorespiratory diseases during summer months (June-August) in the Helsinki metropolitan area, Finland 2001-2017.

\begin{tabular}{|c|c|c|c|c|c|c|c|c|c|c|c|c|}
\hline \multirow{2}{*}{$\begin{array}{l}\text { Disease } \\
\text { Cardiovascula } \\
r\end{array}$} & \multicolumn{3}{|c|}{ All-ages } & \multicolumn{3}{|c|}{ Age18-64 } & \multicolumn{3}{|c|}{ Age 65-74 } & \multicolumn{3}{|c|}{ Age $75+$} \\
\hline & $\begin{array}{l}\text { Media } \\
\mathrm{n}\end{array}$ & $\begin{array}{l}\text { Min } \\
\text {. }\end{array}$ & $\begin{array}{l}\text { Max } \\
.\end{array}$ & $\begin{array}{l}\text { Media } \\
\mathrm{n}\end{array}$ & $\begin{array}{l}\text { Min } \\
.\end{array}$ & $\begin{array}{l}\text { Max } \\
.\end{array}$ & $\begin{array}{l}\text { Media } \\
\mathrm{n}\end{array}$ & $\begin{array}{l}\text { Min } \\
.\end{array}$ & $\begin{array}{l}\text { Max } \\
.\end{array}$ & $\begin{array}{l}\text { Media } \\
\mathrm{n}\end{array}$ & $\begin{array}{l}\text { Min } \\
.\end{array}$ & $\begin{array}{l}\text { Max } \\
.\end{array}$ \\
\hline All & 24 & 6 & 45 & 6 & 0 & 19 & 5 & 0 & 19 & 13 & 2 & 31 \\
\hline $\mathrm{MI}$ & 3 & 0 & 11 & 1 & 0 & 5 & 0 & 0 & 6 & 1 & 0 & 9 \\
\hline IHD & 5 & 0 & 20 & 1 & 0 & 8 & 1 & 0 & 9 & 2 & 0 & 12 \\
\hline $\begin{array}{l}\text { Cerebrovascul } \\
\text { ar }\end{array}$ & 4 & 0 & 12 & 1 & 0 & 7 & 1 & 0 & 7 & 2 & 0 & 10 \\
\hline Arrhythmia & 4 & 0 & 14 & 1 & 0 & 5 & 1 & 0 & 7 & 2 & 0 & 10 \\
\hline \multicolumn{13}{|l|}{ Respiratory } \\
\hline All & 16 & 2 & 37 & 5 & 0 & 20 & 3 & 0 & 12 & 3 & 0 & 12 \\
\hline Asthma & 1 & 0 & 8 & 0 & 0 & 4 & 0 & 0 & 3 & 0 & 0 & 3 \\
\hline COPD & 2 & 0 & 9 & 0 & 0 & 4 & 1 & 0 & 6 & 1 & 0 & 7 \\
\hline Pneumonia & 5 & 0 & 23 & 1 & 0 & 11 & 1 & 0 & 7 & 2 & 0 & 15 \\
\hline
\end{tabular}


Table 2: Daily levels of temperature, relative humidity, barometric pressure and air pollutants during summer months (JuneAugust) in the Helsinki metropolitan area, Finland, 2001-2017.

\begin{tabular}{|l|l|l|l|l|l|l|}
\hline & Mean & Median & Min. & Max. & SD. & $\begin{array}{l}\text { Missing } \\
\text { values }\end{array}$ \\
\hline Meteorology & & & & & & \\
\hline $\begin{array}{l}\text { Temperature } \\
{\left[{ }^{\circ} \mathrm{C}\right]}\end{array}$ & 16.8 & 16.7 & 6.1 & 26.6 & 3.4 & 0 \\
\hline $\begin{array}{l}\text { Relative } \\
\text { Humidity } \\
{[\%]}\end{array}$ & 72 & 73 & 37 & 98 & 12.4 & 0 \\
\hline $\begin{array}{l}\text { Barometric } \\
\text { Pressure } \\
{[\mathrm{hPa}]}\end{array}$ & 1012 & 1012 & 986 & 1034 & 7.1 & 0 \\
\hline $\begin{array}{l}\text { Air pollution } \\
{\left[\mu \mathrm{g} / \mathrm{m}^{3}\right]}\end{array}$ & & & & & & \\
\hline $\mathrm{Ozone}^{\mathrm{PM}}{ }_{2.5}$ & 76.8 & 75.9 & 19.4 & 156.0 & 17.6 & 114 \\
\hline $\mathrm{PM}_{10}$ & 13.6 & 6.6 & 0.5 & 50.2 & 4.6 & 32 \\
\hline $\mathrm{NO}_{2}$ & 17.0 & 16.0 & 2.9 & 62.6 & 7.5 & 23 \\
\hline
\end{tabular}

Table 3 shows the number of heatwave days and mean daily temperature during heatwave and non-heatwave days.

Table 3: Number of heatwave days and mean temperature during heatwave and non-heatwave days during summer months (June-August) in the Helsinki metropolitan area, Finland 2001-2017

\begin{tabular}{|l|l|l|l|}
\hline & $\begin{array}{l}\text { Number of } \\
\text { heatwave } \\
\text { days }\end{array}$ & $\begin{array}{l}\text { Average } \\
\text { temperature } \\
\text { during } \\
\text { heatwaves } \\
{\left[{ }^{\circ} \mathrm{C}\right]}\end{array}$ & $\begin{array}{l}\text { Average } \\
\text { temperature } \\
\text { during } \\
\text { control days } \\
{\left[{ }^{\circ} \mathrm{C}\right]}\end{array}$ \\
\hline $\begin{array}{l}\mathbf{9 0}^{\text {th }} \\
\text { percentile }\end{array}$ & 113 & 22.8 & 16.3 \\
\hline $\begin{array}{l}\text { All } \\
\text { heatwaves }\end{array}$ & 62 & 22.6 & 16.3 \\
\hline $\begin{array}{l}\text { Short } \\
\text { heatwaves }\end{array}$ & 51 & 23.1 & 16.3 \\
\hline $\begin{array}{l}\text { Long } \\
\text { heatwaves }\end{array}$ & & & 16.6 \\
\hline $\begin{array}{l}\mathbf{9 5}^{\text {th }} \\
\text { percentile }\end{array}$ & 60 & 23.9 & \\
\hline $\begin{array}{l}\text { All } \\
\text { Heatwaves }\end{array}$ & & & \\
\hline
\end{tabular}

Table 4 shows the associations of daily temperature with hospital admissions due to cardiorespiratory diseases. No statistically significant increased risk was found for hospital admissions in association with daily mean temperature for any of the disease categories. There was a suggestive positive association for arrhythmia admissions in the 65-74 age group. Respiratory diseases 
showed a statistically significant protective association in the all-ages group while asthma showed significant protective association for all-ages and 65-74 years age group. All cardiovascular diseases and COPD showed borderline significant protective associations in the 18-64 and 75 plus years age groups, respectively.

Table 4: Percentage change $(95 \% \mathrm{Cl})$ in daily hospital admissions for cardiorespiratory diseases associated with $1^{\circ} \mathrm{C}$ increase in daily mean temperature during summer months (June-August), 2000-2017, Helsinki, Finland.

\begin{tabular}{|l|l|l|l|l|}
\hline Disease & All-ages & Age 18-64 & Age 65-74 & Age 75 + \\
\hline Cardiovascular & & & & \\
\hline All & $-0.49(-1.14,0.17)$ & $-1.21(-2.47,0.07)$ & $0.02(-1.38,1.44)$ & $-0.32(-1.22,0.60)$ \\
\hline MI & $0.14(-1.70,2.02)$ & $-0.17(-3.50,3.28)$ & $0.36(-3.52,4.39)$ & $0.16(-2.51,2.90)$ \\
\hline IHD & $-0.46(-1.79,0.88)$ & $-0.73(-3.22,1.82)$ & $-0.40(-3.14,2.42)$ & $-0.37(-2.26,1.57)$ \\
\hline Cerebrovascular & $-0.70(-2.22,0.85)$ & $-0.89(-3.78,2.09)$ & $-1.37(-4.44,1.81)$ & $-0.19(-2.38,2.06)$ \\
\hline Arrhythmia & $-0.66(-2.24,0.95)$ & $-2.44(-5.58,0.80)$ & $2.95(-0.48,6.50)$ & $-1.52(-3.69,0.69)$ \\
\hline Respiratory & & & & \\
\hline All & $-1.09(-1.88,-0.30)$ & $0.53(-0.90,1.97)$ & $-0.59(-2.43,1.28)$ & $-0.11(-1.45,1.25)$ \\
\hline Asthma & $-3.49(-6.25,-0.65)$ & $3.25(-2.11,8.91)$ & $-8.96(-16.42,-0.82)$ & $-2.68(-8.06,3.01)$ \\
\hline COPD & $-0.53(-2.56,1.55)$ & $1.54(-2.81,6.09)$ & $0.97(-2.60,4.67)$ & $-2.59(-5.57,0.49)$ \\
\hline Pneumonia & $-0.30(-1.67,1.09)$ & $-0.66(-3.17,1.92)$ & $-0.33(-3.47,2.92)$ & $1.12(-0.94,3.22)$ \\
\hline
\end{tabular}

Associations between heatwaves and cardiorespiratory hospital admissions varied depending on the type of disease (Table 5). In the analysis where $90^{\text {th }}$ percentile of the temperature distribution was used as a cutoff point, statistically significant positive associations were detected between all heatwaves and pneumonia in all-ages and 18-64 age group and also all respiratory diseases in 1864 age group. We also found suggestive increased risk for cerebrovascular disease in all-ages and COPD hospitalizations in 18-64 age group. Protective effects were detected for arrhythmia. When short heatwaves were analyzed separately, we found significant positive associations also with COPD admissions in the 18-64 year age group and Ml among persons 65-74 years of age.

Long heatwaves $\left(90^{\text {th }}\right.$ percentile cutoff point) and more intense heatwaves (95th percentile) showed significant increased risk for all respiratory hospitalizations in elderly people (75 years of age and above). For hospital admissions due to pneumonia, there was a statistically significant positive association with long heatwaves and a suggestive positive association with intense heatwaves in those aged $\geq 75$.

\section{Sensitivity Analyses}

We evaluated the robustness of our results by performing sensitivity analyses. Results remained essentially the same (the results not shown). 
Table 5: Percentage change $(95 \% \mathrm{Cl})$ in daily hospital admissions for cardiorespiratory diseases associated with heatwave days in summer months (June-August), 2000-2017, Helsinki, Finland

\begin{tabular}{|c|c|c|c|c|c|}
\hline Heatwaves & & All-ages & Age 18-64 & Age $65-74$ & Age $75+$ \\
\hline $\begin{array}{l}90^{\text {th }} \\
\text { Percentile } \\
\text { cut-off, } \\
\text { All } \\
\text { heatwaves }\end{array}$ & $\begin{array}{l}\text { Cardiovascular } \\
\text { All } \\
\text { MI } \\
\text { IHD } \\
\text { Cerebrovascular } \\
\text { Arrhythmia } \\
\text { Respiratory } \\
\text { All } \\
\text { Asthma } \\
\text { COPD } \\
\text { Pneumonia }\end{array}$ & $\begin{array}{l}-2.14(-7.71,3.76) \\
4.77(-11.03,23.38) \\
0.06(-11.24,12.79) \\
12.17(-1.93,28.29) \\
-20.78(-31.81,-7.97) \\
4.18(-3.04,11.94) \\
-4.36(-27.46,26.08) \\
-5.03(-20.95,14.10) \\
20.48(6.85,35.85)\end{array}$ & $\begin{array}{l}-7.57(-17.73,3.84) \\
-6.82(-31.64,27.00) \\
-3.50(-23.35,21.49) \\
12.12(-14.10,46.35) \\
-34.41(-52.71,-9.03) \\
17.97(3.97,33.86) \\
17.86(-28.57,94.46) \\
48.05(0.00,119.20) \\
28.94(3.00,61.42)\end{array}$ & $\begin{array}{l}2.01(-10.00,15.62) \\
40.42(-0.43,98.04) \\
9.62(-14.50,40.55) \\
17.96(-10.56,55.57) \\
-13.13(-35.68,17.31) \\
-6.11(-20.27,10.57) \\
-33.27(-68.73,42.42) \\
-9.48(-33.48,23.18) \\
25.67(-4.24,64.93)\end{array}$ & $\begin{array}{l}-0.57(-8.30,7.81) \\
-3.55(-23.81,22.09) \\
-2.81(-18.03,15.23) \\
10.07(-8.85,32.93) \\
-18.44(-33.63,0.24) \\
10.18(-2.05,23.94) \\
38.56(-15.15,126.25) \\
-20.67(-40.38,5.55) \\
18.25(-0.82,40.98)\end{array}$ \\
\hline $\begin{array}{l}90^{\text {th }} \\
\text { Percentile } \\
\text { cutoff, } \\
\text { Short } \\
\text { heatwaves }\end{array}$ & $\begin{array}{l}\text { Cardiovascular } \\
\text { All } \\
\text { MI } \\
\text { IHD } \\
\text { Cerebrovascular } \\
\text { Arrhythmia } \\
\text { Respiratory } \\
\text { All } \\
\text { Asthma } \\
\text { COPD } \\
\text { Pneumonia }\end{array}$ & $\begin{array}{l}-1.32(-8.05,5.91) \\
17.13(-3.44,42.07) \\
8.47(-5.70,24.78) \\
12.27(-4.19,31.56) \\
-26.85(-39.36,-11.76) \\
\\
5.24(-3.58,14.86) \\
21.58(-10.78,65.68) \\
-6.98(-25.78,16.58) \\
20.31(3.49,39.87)\end{array}$ & $\begin{array}{l}-3.64(-16.10,10.68) \\
5.21(-28.12,54.01) \\
2.63(-22.04,35.11) \\
19.07(-12.40,61.84) \\
-33.82(-55.37,-1.87) \\
\\
27.03(9.49,47.38) \\
47.11(-18,23,164.64) \\
65.33(3.13,165.06) \\
48.30(13.87,93.15)\end{array}$ & $\begin{array}{l}3.48(-11.15,20.53) \\
74.86(15.75,164.16) \\
21.29(-9.64,62.81) \\
4.48(-25.99,47.49) \\
-10.75(-38.04,28.56) \\
-3.89(-21.44,17.59) \\
0.23(-57.34,135.48) \\
-10.06(-38.48,31.50) \\
33.99(-4.80,88.59)\end{array}$ & $\begin{array}{l}-1.76(-10.92,8.35) \\
2.36(-21.99,34.31) \\
5.47(-13.30,28.31) \\
12.23(-9.94,39.87) \\
-32.07(-48.07,-11.15) \\
-1.04(-14.72,14.85) \\
72.41(-1.01,200.29) \\
-28.29(-49.87,2.59) \\
-0.30(-21.09,25.96)\end{array}$ \\
\hline $\begin{array}{l}90^{\text {th }} \\
\text { Percentile } \\
\text { cutoff, } \\
\text { Long } \\
\text { heatwaves }\end{array}$ & $\begin{array}{l}\text { Cardiovascular } \\
\text { All } \\
\text { MI } \\
\text { IHD } \\
\text { Cerebrovascular } \\
\text { Arrhythmia } \\
\text { Respiratory } \\
\text { All } \\
\text { Asthma }\end{array}$ & $\begin{array}{l}-3.01(-11.46,6.24) \\
-12.85(-32.96,13.31) \\
-13.36(-28.82,5.47) \\
7.87(-13.15,33.98) \\
-8.34(-26.27,14.57) \\
-1.01(-11.29,10.46) \\
-52.46(-71.80, .19 .74)\end{array}$ & $\begin{array}{l}-13.56(-28.14,3.97) \\
-18.09(-49.11,31.86) \\
-11.50(-38.68,27.73) \\
-12.16(-43.75,37.16) \\
-29.16(-57-62,18.40) \\
-0.85(-18.99,21.35) \\
-22.69(-67.96,86.48)\end{array}$ & $\begin{array}{l}-1.46(-18.64,19.35) \\
-6.02(-44.48,59.11) \\
-6.97(-37.40,38.24) \\
38.92(-7.90,109.53) \\
-24.17(-52,31,20.57) \\
-12.54(-31.42,11.54) \\
-76.19(-93.91,-6.86)\end{array}$ & $\begin{array}{l}2.50(-9.60,16.23) \\
-12.16(-40.86,30.47) \\
-17.85(-38.41,9.58) \\
4.53(-23.67,43.14) \\
10.09(-18.10,47.98) \\
22.47(3.14,45.43) \\
-25.76(-67.86,71.52)\end{array}$ \\
\hline
\end{tabular}




\section{Discussion:}

This study investigated the associations of daily mean temperature and heatwaves with hospital admissions for cardiorespiratory diseases in summer months (June-August) in the Helsinki metropolitan area, Finland. We found that daily mean temperature was associated with decreased risk of hospitalization for respiratory diseases, asthma, and to lesser extent cardiovascular diseases. In contrast, during heatwaves the risk of hospitalization was increased due to pneumonia, and in some age groups for respiratory diseases in general, COPD and MI. We also found a negative association of heatwaves with arrhythmia hospitalizations.

Our study results showed no increased risk for total cardiovascular admissions in association with daily mean temperature and heatwaves. These findings are in line with a review; in which Turner et al. found no association between summer temperature and cardiovascular morbidity (23). Likewise, previous literature has shown either no or weak association between heat and cardiovascular morbidity $(30,31,32,33)$. One of the potential reasons could be that most of the vulnerable people with acute cardiovascular events might die before reaching to hospital which can explain the low cardiovascular hospital admissions (34).

Our results suggest that heatwaves may yet be associated with specific subtypes of cardiovascular diseases. We found borderline significant association between heatwaves and cerebrovascular admissions in all-ages group. However, there has been no evidence in previous literature for association of heat and heatwaves with cerebrovascular admissions. An overview of the systematic reviews found no association of cerebrovascular disease hospitalizations with heat (35). Our findings also indicated positive association of heatwaves with myocardial infarction admissions in 65-74 year old persons. However, previous studies have found no or a decreased risk of $\mathrm{Ml}$ admissions during summer months $(26,36,37)$.

We also observed a protective association of arrhythmia admissions with heatwaves. A population based study from Canada did not find any association between heat and arrhythmia admissions (38). There are too few studies to draw conclusions about the association between heat and arrhythmia hospital admissions.

We found a positive association of heatwaves with hospital admissions due to respiratory diseases in general, pneumonia and COPD. These results are consistent with the findings from previous studies on respiratory morbidity $(15,39,40,41)$. The possible explanation for a stronger association between heatwaves and respiratory admissions than between heatwaves and cardiovascular diseases is that respiratory diseases are not as acutely fatal as cardiovascular diseases. This means that more people are able to reach hospitals (42). In extreme heat, human body maintains safe body temperature through thermoregulation which is associated with increase in skin blood flow, cardiac output and pulmonary ventilation. Though body heat is lost by sweating, hyperthermia can cause hyperventilation leading to thermal hyperpnea (increase in respiratory rate and tidal volume). These responses from thermoregulatory mechanism can lead to an increase in risk for respiratory and COPD hospitalizations $(43,44)$. Andreson et al. (2013) 
argued that, in addition to the thermoregulatory response, acute respiratory effects may also be caused by the direct effect of breathing hot air (45).

In our study long heatwaves and more intense heatwaves ( $95^{\text {th }}$ percentile cutoff point) were associated with risk of total respiratory and pneumonia hospitalizations only in the oldest age category. These findings are in line with other studies which reported elderly people as the most vulnerable group for respiratory morbidity effects in extreme and long heatwaves $(46,47,48)$. However, with different definitions of heatwaves we also found associations between heatwaves and respiratory health in the age group 18-64.

The risk of morbidity association with heatwaves may vary with length and intensity. A study by Levy et al. showed that length of heatwaves increase the risk of emergency department arrivals (49). Likewise, a study in Australia also found increase in infant's hospitalizations with duration of heatwave (50). The effect of heatwaves on morbidity may vary across different regions and still needs more investigation.

Finland, being a North European country, has cold summer temperatures. This is most likely the reason that we found no positive associations or even some protective associations in connection with daily temperature. However, our results further suggested that heatwaves pose a public health concern regarding morbidity (as indicated by hospital admissions).

One of the strengths of our study is that it was conducted in a Northern climate where only few studies have taken place. We used long time series data and had in practice a hundred percent coverage of hospital admissions. Thus reliable evidence on population level associations could be provided. Also, this study evaluated the associations of temperature with cause-specific diagnosis and in age groups rather than for broader disease categories and total population. The potential confounding effect of air pollution was controlled using all major indicators of air pollution. However, this study has some limitations as well. We were not able to include persons younger than 18 years because the limited number of cases in the age group would have led to imprecise effect estimates. Also, the study only included cardiovascular and respiratory hospital admissions. Admissions due to other causes could also be affected by heat exposure.

\section{Conclusion:}

In conclusion, we found no associations and even protective associations between daily mean temperature and cardiorespiratory hospital admissions. However, our results suggest that heatwaves are a health threat and affect morbidity even in the northern climate. Moreover, not only the elderly are at risk but preventive programs should also take other age groups into account.

\section{Acknowledgments:}

This publication was supported by the funding from University of Eastern Finland, Ministry of Social Affairs and Health and the Academy of Finland (project number 329304). 


\section{Author contributions:}

Conceptualization, Hasan Bin Sohail, Virpi Kollanus and Timo Lanki; Data curation, Hasan Bin Sohail, Pekka Tiittanen, Virpi Kollanus and Timo Lanki; Formal analysis, Hasan Bin Sohail, Pekka Tiittanen and Timo Lanki; Funding acquisition, Timo Lanki; Investigation, Hasan Bin Sohail, Pekka Tiittanen, Virpi Kollanus and Timo Lanki; Methodology, Hasan Bin Sohail, Pekka Tiittanen and Timo Lanki; Project administration, Timo Lanki; Resources, Timo Lanki; Supervision, Alexandra Schneider and Timo Lanki; Validation, Pekka Tiittanen; Writing - original draft, Hasan Bin Sohail; Writing review \& editing, Hasan Bin Sohail, Pekka Tiittanen, Virpi Kollanus, Alexandra Schneider and Timo Lanki.

\section{Conflict of Interest:}

The authors declare no conflict of interest. 


\section{References}

1. IPCC, 2014: Climate Change 2014: Synthesis Report. Contribution of Working Groups I, II and III to the Fifth Assessment Report of the Intergovernmental Panel on Climate Change [Core Writing Team, R.K. Pachauri and L.A. Meyer (eds.)]. IPCC, Geneva, Switzerland, 151 pp.

2. Kenny GP, Yardley J, Brown C, Sigal RJ, Jay O. Heat stress in older individuals and patients with common chronic diseases. CMAJ. 2010;182(10):1053-1060. doi:10.1503/cmaj.081050

3. Kovats RS, Hajat S. Heat stress and public health: a critical review. Annu Rev Public Health 2008;29:41-55

4. Gasparrini A, Guo Y, Hashizume M, Lavigne E et al. Mortality risk attributable high and low temperature: a multicounty observations study. The Lancet. 2015; doi: https://doi.org/10.1016/S0140-6736(14)62114-0.

5. Guo Y, Gasparrini A, Armstrong BG, et al. Heat Wave and Mortality: A Multicountry, Multicommunity Study. Environ Health Perspect. 2017;125(8):087006. Published 2017 Aug 10. doi:10.1289/EHP1026

6. Baccini M, Biggeri A, Accetta G, et al. Heat effects on mortality in 15 European cities. Epidemiology. 2008;19(5):711-719. doi:10.1097/EDE.0b013e318176bfcd

7. D'Ippoliti, D., Michelozzi, P., Marino, C. et al. The impact of heat waves on mortality in 9 European cities: results from the EuroHEAT project. Environ Health 9, 37 (2010). https://doi.org/10.1186/1476-069X-9-37

8. Anderson BG, Bell ML. Weather-related mortality: how heat, cold, and heat waves affect mortality in the United States. Epidemiology. 2009;20(2):205-213. doi:10.1097/EDE.0b013e318190ee08

9. Casanueva A, Burgstall A, Kotlarski S, et al. Overview of Existing Heat-Health Warning Systems in Europe. Int J Environ Res Public Health. 2019;16(15):2657. Published 2019 Jul 25. doi:10.3390/ijerph16152657

10. Li M., Gu S., Bi P., Yang J., Liu Q. Heat waves and morbidity: Current knowledge and further direction-a comprehensive literature review. Int. J. Environ. Res. Public Health. 2015;12:5256-5283. doi: 10.3390/ijerph120505256.

11. Åström D.O., Forsberg B., Röcklov J. Heat wave impact on morbidity and mortality in the elderly population: $\mathrm{A}$ review of recent studies. Maturitas. 2011;69:99-105. doi: 10.1016/j.maturitas.2011.03.008.

12. Knowlton K, Rotkin-Ellman M, King G, et al. The 2006 California heat wave: impacts on hospitalizations and emergency department visits. Environ Health Perspect. 2009;117(1):61-67. doi:10.1289/ehp.11594

13. Liss, A., Wu, R., Chui, K. et al. Heat-Related Hospitalizations in Older Adults: An Amplified Effect of the First Seasonal Heatwave. Sci Rep 7, 39581 (2017). https://doi.org/10.1038/srep39581

14. Hopp S, Dominici F, Bobb JF. Medical diagnoses of heat wave-related hospital admissions in older adults. Prev Med. 2018;110:81-85. doi:10.1016/j.ypmed.2018.02.001

15. Gronlund C.J., Zanobetti A., Schwartz J.D., Wellenius G.A., O'Neill M.S. Heat, heat waves, and hospital admissions among the elderly in the United States, 1992-2006. Environ. Health Perspect. 2014;122:11871192. doi: 10.1289/ehp.1206132

16. Michelozzi, P., Accetta, G., De Sario, M., D'Ippoliti, D., Marino, C., Baccini, M., et al. PHEWE Collaborative Group (2009). High temperature and hospitalizations for cardiovascular and respiratory causes in 12 European cities. American journal of respiratory and critical care medicine, 179(5), 383-389. https://doi.org/10.1164/rccm.200802-2170C

17. Anderson, G. B., Dominici, F., Wang, Y., McCormack, M. C., Bell, M. L., \& Peng, R. D. (2013). Heat-related emergency hospitalizations for respiratory diseases in the Medicare population. American journal of respiratory and critical care medicine, 187(10), 1098-1103. https://doi.org/10.1164/rccm.201211-19690C

18. Hansen A., Bi P., Nitschke M., Ryan P., Pisaniello D., Tucker G. The effect of heat waves on mental health in a temperate Australian city. Environ. Health Perspect. 2008;116:1369-1375. doi: 10.1289/ehp.11339.

19. Ha S., Talbott E.O., Kan H., Prins C.A., Xu X. The effects of heat stress and its effect modifiers on stroke hospitalizations in Allegheny County, Pennsylvania. Int. Arch. Occup. Environ. Health. 2014;87:557-565. doi: 10.1007/s00420-013-0897-2

20. Zhiwei Xu, Shilu Tong, Jian Cheng, Yuzhou Zhang et al. Heatwaves, hospitalizations for Alzheimer's disease, and post discharge deaths: A population-based cohort study, Environmental Research, Volume 178, 2019, 108714, ISSN 0013-9351, https://doi.org/10.1016/j.envres.2019.108714.

21. Linares C, Martinez-Martin P, Rodríguez-Blázquez C, Forjaz MJ, Carmona R, Díaz J. Effect of heat waves on morbidity and mortality due to Parkinson's disease in Madrid: A time-series analysis. Environ Int. 2016;8990:1-6. doi:10.1016/j.envint.2016.01.017

22. Bhaskaran K, Hajat S, Haines A, Herrett E, Wilkinson P, Smeeth L. Effects of ambient temperature on the incidence of myocardial infarction. Heart. 2009;95:1760-1769. doi: 10.1136/hrt.2009.175000 
23. Turner LR, Barnett AG, Connell D, Tong S. Ambient temperature and cardiorespiratory morbidity: a systematic review and meta-analysis. Epidemiol (Camb Mass) 2012;23:594-606. doi: 10.1097/EDE.0b013e3182572795

24. Screen JA, Simmonds I. 2010. The central role of diminishing sea ice in recent Arctic temperature amplification. Nature 464:1334-1337.

25. Wichmann J, Andersen Z, Ketzel M, Ellermann T, Loft S. Apparent temperature and cause-specific emergency hospital admissions in Greater Copenhagen, Denmark. PLoS One. 2011;6(7):e22904. doi:10.1371/journal.pone.0022904

26. Wichmann J, Ketzel M, Ellermann T, Loft S. Apparent temperature and acute myocardial infarction hospital admissions in Copenhagen, Denmark: a case-crossover study. Environ Health. 2012;11:19. Published 2012 Mar 30. doi:10.1186/1476-069X-11-19

27. Rocklov J, Forsberg B. Comparing approaches for studying the effects of climate extremes - a case study of hospital admissions in Sweden during an extremely warm summer. Glob Health Action 2009;2

28. Key figures on population by Area, Information and Year-Tilastokeskuksen PX-Web tietokannat. (2020). Available http://pxnet2.stat.fi/PXWeb/pxweb/en/StatFin/StatFin_vrm vaerak/statfin_vaerak_pxt_11ra.px/

29. R Development Core Team (2008). R: A Language and Environment for Statistical Computing. R Foundation foBasr Statistical Computing, Vienna, Austria. ISBN 3-900051-00-3, URL: http: //www.R-project.org/

30. R. Basu, D. Pearson, B.Malig, et al. The effect of high ambient temperature on emergency room visits. Epidemiology, 23(2012), pp.813-820.

31. K.L.Ebi, K.A.Exuzides, E.Lau, M. Kelsh, A.Barnston. Weather changes associated with hospitalizations for cardiovascular diseases and stroke in California, 1983-1998. Int.J. Biometeorol., 49(2004), pp.48-58.

32. J. Wichmann, Z.Amdersen, M. Ketzel, T. Ellermann, S.Loft. Apparent temperature and cause-specific emgergency hospital admissions in Greater Copenhagen, Denmark. Plos ONE, 6 (2011), Article e22904

33. L.Turner, D. Connell, S.Tong. Exposure to hot and cold temperatures and ambulance attendances in Brisbane, Australia: a time-series study. BMJ open, 2(2012), Article e001074

34. P. Michelozzi, G. Accetta, M. Desario, et al. High temperature and hospitalizations for cardiovascular and respiratory causes in 12 Europran cities. American of Respiratory and Critical Care Medicine, 179(2009), pp.383-389.

35. Song X, Wang S, Hu Y, Yue M, Zhang T, Liu Y et al. Impact of ambient temperature on morbidity and mortality: An overview of review. Sci Total Environ. Available at: https://www.sciencedirect.com/science/article/pii/S0048969717302292

36. Bhaskaran K, Hajat S, Haines A. et al. Short term effects of temperature on risk of myocardial infarction in England and Wales: time series regression analysis of the Myocardial Ischaemia National Audit Project (MINAP) registry. BMJ. 2010;341:c3823

37. Abrignani M, Corrao S, Biondo G. et al. Influence of climatic variables on acute myocardial infarction hospital admissions. Int J Cardiol. 2009;137:123-9.

38. Bai, Li; Li, Qiongsi; Wang, Jun; Lavigne, Eric; Gasparrini, Antonio; Copes, Ray; Yagouti, Abderrahmane; Burnett, Richard T; Goldberg, Mark S; Villeneuve, Paul J; +2 more... Cakmak, Sabit; Chen,Hong; (2016) Hospitalizations from Hypertensive Diseases, Diabetes, and Arrhythmia in Relation to Low and High Temperatures: Population-Based Study. Nature, 6 (1). 30283

39. Anderson GB, Dominici F, Wang Y, McCormack MC, Bell ML, Peng RD. Heat-related emergency hospitalizations for respiratory diseases in the Medicare population. Am J Respir Crit Care Med. 2013;187(10):1098-1103.

40. Green RS, Basu R, Malig B, Broadwin R, Kim JJ, Ostro B. The effect of temperature on hospital admissions in 9 California counties. Int J Public Health. 2010;55(2):113-121.

41. Mastrangelo G, Fedeli U, Visentin C, Milan G, Fadda E, Spolaore P. Pattern and determinants of hospitalization during heat waves: an ecologic study. BMC Public Health. 2007;7:200

42. White MD. Components and mechanisms of thermal hyperpnea. J Appl Physiol 2006;101:655-663.

43. Leon LR, Helwig BG. Heat stroke: role of the systemic inflammatory response. J Appl Physiol 2010;109:19801988

44. Sprung CL. Heat stroke: modern approach to an ancient disease. Chest 1980;77:461-462.

45. Anderson, G. B., Dominici, F., Wang, Y., McCormack, M. C., Bell, M. L., \& Peng, R. D. (2013). Heat-related emergency hospitalizations for respiratory diseases in the Medicare population. American journal of respiratory and critical care medicine, 187(10), 1098-1103. https://doi.org/10.1164/rccm.201211-19690C

46. Zhang A, Hu W, Li J, Wei R, Lin J, Ma W. Impact of heatwaves on daily outpatient visits of respiratory disease: A time-stratified case-crossover study. Environ Res. 2019 Feb 1;169:196-205. pmid:30466013 
47. Song X, Wang S, Li T, Tian J, Ding G, Wang J, et al. The impact of heat waves and cold spells on respiratory emergency department visits in Beijing, China. Sci Total Environ. 2018 Feb 15;615:1499-505. pmid:28923709

48. Martínez-Solanas, È., \& Basagaña, X. (2019). Temporal changes in the effects of ambient temperatures on hospital admissions in Spain. PloS one, 14(6), e0218262. https://doi.org/10.1371/journal.pone.0218262

49. Levy M, Broccoli M, Cole G, Jenkins JL, Klein EY. An analysis of the relationship between the heat index and arrivals in the emergency department. PLoS Curr. 2015;7

50. Heatwave and infants' hospital admissions under different heatwave definitions. Environ Pollut. 2017;229:525. 